\title{
A construção social de uma escola quilombola: a experiência da Comunidade Caveira, RJ
}

\author{
David Gonçalves Soares' (D) \\ Kalyla Maroun" (D) \\ Antonio Jorge Gonçalves Soares" (D)
}

\begin{abstract}
RESUMO
$\mathrm{O}$ artigo tem por objetivo descrever e analisar o processo de construção social de uma escola quilombola e seu currículo, identificando atores sociais, processos de agenciamento e disputas de sentido sobre Educação Escolar Quilombola. Apresenta um estudo de caso da Escola Municipal Quilombola Dona Rosa Geralda, no município de São Pedro da Aldeia, Rio de Janeiro, com observações etnográficas e entrevistas realizadas na escola, na comunidade e na Secretaria Municipal de Educação entre os anos de 2017 e 2019. Entre os resultados, destacam-se: a presença de um forte sentido atribuído à escola enquanto agenciadora da identidade comunitária; a apropriação por seus profissionais de elementos discursivos associados aos movimentos negros enquanto resoluções curriculares disponíveis de tradução das políticas de educação quilombola; e a existência de mediações e dilemas que compõem essa experiência e que podem fornecer elementos para uma agenda de pesquisa.
\end{abstract}

PALAVRAS-CHAVE

educação e identidade; educação quilombola; currículo diferenciado.

'Universidade Federal Fluminense, Niterói, RJ, Brasil.

"Universidade Federal do Rio de Janeiro, Rio de Janeiro, RJ, Brasil. 


\title{
THE SOCIAL CONSTRUCTION OF A QUILOMBOLA SCHOOL: THE EXPERIENCE OF THE CAVEIRA COMMUNITY, RJ
}

\begin{abstract}
This article aims to describe and analyze the social construction of a quilombola school and its curriculum, identifying relevant actors, agency processes, and disputes of meaning about Quilombola School Education. It outlines a case study conducted at Dona Rosa Geralda, a Quilombola Municipal School, in the municipality of São Pedro da Aldeia, state of Rio de Janeiro, with ethnographic observations and interviews conducted at the school, in the community, and in the Municipal Department of Education, from 2017 to 2019. Among the results, the following stand out: the existence of a strong meaning attributed to the school as an agency of community identity; the appropriation by its professionals of discursive elements associated with the black movement, as curricular resolutions available for translating quilombola educational policies; and the existence of mediations and dilemmas that make up this experience and that can provide elements for a research agenda.
\end{abstract}

KEYWORDS

education and identity; quilombola education; differentiated curriculum.

\section{LA CONSTRUCCIÓN SOCIAL DE UNA ESCUELA QUILOMBOLA: LA EXPERIENCIA DE LA COMUNIDAD CAVEIRA, RJ}

\section{RESUMEN}

El artículo tuve como objetivo describir y analizar el proceso de construcción social de una escuela quilombola y su currículo, identificando actores sociales, procesos de agencia y disputas de significado sobre la Educación Escolar Quilombola. Presenta un estudio de caso en la Escuela Municipal Quilombola Dona Rosa Geralda, en el municipio de São Pedro da Aldeia, Rio de Janeiro, con observaciones etnográficas y entrevistas realizadas en la escuela, en la comunidad y en el Departamento de Educación Municipal, entre 2017 y 2019. Entre los resultados, se destacan: la presencia de un fuerte sentido atribuido a la escuela como agente de identidad comunitaria; la apropiación por parte de sus profesionales de elementos discursivos asociados con el Movimiento Negro como resoluciones curriculares disponibles para la traducción de las políticas educativas quilombolas; $y$ la existencia de mediaciones y dilemas que conforman esta experiencia y que pueden proporcionar elementos para una agenda de investigación.

\section{PALABRAS CLAVE}

educación e identidad; educación quilombola; currículo diferenciado. 


\section{INTRODUÇÃO}

Do ponto de vista normativo (Brasil,2012), a Educação Escolar Quilombola (EEQ) é uma modalidade de ensino que deve ser ofertada por estabelecimentos de ensino localizados em territórios quilombolas, ou que atendam estudantes oriundos destes, nas diferentes etapas e modalidades da Educação Básica. As Diretrizes Curriculares Nacionais para a Educação Escolar Quilombola fundamentam-se nas seguintes prerrogativas: memória coletiva; línguas reminiscentes; marcos civilizatórios; práticas culturais; tecnologias e formas de produção do trabalho; acervos e repertórios orais; festejos, usos, tradições e demais elementos que conformam o patrimônio cultural das comunidades quilombolas de todo o país; e, por fim, territorialidade (Brasil, 2012). Tais diretrizes trazem termos como: "pedagogia própria", "respeito à especificidade étnico-cultural de cada comunidade", "grupos culturalmente diferenciados", "formas próprias de organização social", necessidade de "elaboração de materiais didático-pedagógicos contextualizados com a identidade étnico-racial do grupo" (Brasil, 2012) e outras expressões correlatas que denotam o ancoramento da EEQ às diferentes realidades socioculturais às quais cada comunidade quilombola está submetida.

É inegável que o processo de implementação da política de educação quilombola, representada por suas respectivas diretrizes curriculares, tem colocado desafios para o modelo clássico de escola republicana - a começar pela forte associação entre o devir da escola e o devir da comunidade local prevista em suas normativas. O programa institucional clássico, conforme expressão cunhada por Dubet (2011), que estaria associado ao modelo da escola republicana, baseava-se no estabelecimento de um contraponto às formas de pertencimento e vinculação primárias dos indivíduos em formação. Justamente pela afirmação da noção de indivíduo que deve ser proprietário de seu próprio corpo e destino, sem submissão às determinações da família, seja pela linhagem, seja pela pertença direta às comunidades que definem o seu lugar e suas redes de proteção (Castel, 2005). Dessa forma, esperava-se que a escola republicana, por meio de seus ritos, suas disciplinas e sua moral, formasse nos indivíduos novas disposições sociais, que embora não enublassem as disposições familiares e comunitárias poderiam dotá-los de relativa autonomia quanto a novos caminhos e decisões diante dessas instâncias. Esse contraponto fornecido pela ação educadora da escola não apenas garantiria a produção de um novo tipo de indivíduo, especialmente cidadãos nacionais de democracias liberais, para além das disposições conferidas por seus grupos primários, mas, no limite, poderia promover até mesmo um questionamento das configurações de solidariedade social e de autoridades legítimas, tanto familiares quanto comunitárias.

Do ponto de vista analítico (Arruti, 2017; Maroun e Carvalho, 2017), a EEQ parte de uma perspectiva diferente daquela descrita anteriormente, dando destaque à importância da interface entre práticas e saberes pertencentes à tradição escolar de forma geral e práticas e saberes singulares compartilhados no interior de cada uma das comunidades que compõem o heterogêneo universo dos quilombos no Brasil. Menos contrastiva, idealmente mais conciliatória, seu tipo-ideal desenhado nas normativas nacionais afirma que a EEQ estaria inseparavelmente associada à 
memória, às formas de solidariedade e autoridade locais e, ao mesmo tempo, deveria tratar do conhecimento ou dos saberes universais previstos no currículo básico.

O conceito contemporâneo de quilombo, apesar de suas disputas de significado (Jorge, 2016; Miranda, 2018) ou dos processos de ressemantização (Arruti, 2006), refere-se a grupos que se autointitulam remanescentes de quilombos e apresentam algumas características comuns, tais como: uma organização social específica, com base em laços de solidariedade e parentesco; uma territorialidade caracterizada pelo uso comum da terra; uma origem ou ancestralidade comum; o compartilhamento de uma memória coletiva sobre o histórico de ocupação da terra e da formação do grupo; uma identidade coletiva (re)construída ou em processo de (re)construção, reivindicada por hábitos, rituais e/ou saberes partilhados (Arruti, 2006). Nessa direção, tal conceito engloba em sua formulação o pressuposto de que cada comunidade quilombola tem seu próprio processo de construção e reafirmação identitária, o que indica a ausência de um modelo prontamente disponível que possa vir a determinar como esses grupos se formaram e se autointitularam como tais.

As comunidades quilombolas, enquanto sujeitos de direitos, ainda são realidades relativamente recentes na história republicana nacional, já que muitas delas ainda estão em processo de reconhecimento ou titulação (Jorge, 2016). Se pensarmos que um modelo normativo de EEQ surge somente após a publicação de suas diretrizes, em 2012, podemos afirmar que estamos diante de processos de construção e legitimação, tanto para a educação diferenciada ${ }^{1}$ quanto para o fortalecimento das identidades étnicas de tais grupos (Barth, 2000). Devemos marcar que a EEQé ainda um objeto em construção, passível de experimentações por parte de gestores dos sistemas educacionais, de agentes escolares e das próprias comunidades. Tal como adverte Arruti (2017, p. 109), “a educação escolar quilombola não é nem uma realidade da qual possamos propor um retrato preciso, nem uma proposta pedagógica específica ou uma política pública definida". Todavia, a indissociabilidade entre os rumos das escolas e das comunidades quilombolas já se tornou experiência concreta no cenário do sistema público de educação. Para Maroun e Carvalho (2017), que analisaram duas escolas quilombolas em contextos diferenciados por meio de etnografia, as experiências de EEQ podem se mostrar tão distintas quanto o próprio processo de formação e autoatribuição das próprias comunidades.

Nesse sentido, este artigo tem como objetivo descrever e analisar o processo de construção social de uma escola quilombola e de seu currículo diferenciado, identificando atores relevantes, processos de agenciamento, disputas de sentido e interpretações concorrentes sobre a EEQ, entre outros. Trata-se da Escola Municipal Quilombola Dona Rosa Geralda da Silveira — única escola do gênero pertencente à rede municipal de São Pedro Aldeia, Rio de Janeiro e a primeira do estado do Rio de Janeiro a ter o título quilombola em seu nome.

1 A noção de educação diferenciada está diretamente vinculada aos processos de aprendizagem, escolares ou não, das comunidades tradicionais. No âmbito escolar, a educação diferenciada deve se situar para além dos currículos universais, incorporando conhecimentos tradicionais e suas práticas de transmissão. 
Os dados empíricos acumulados para o desenvolvimento do texto em tela resultam de observações etnográficas e entrevistas realizadas na referida escola, na comunidade quilombola Caveira ${ }^{2}$ e na Secretaria Municipal de Educação de São Pedro da Aldeia, entre os anos de 2017 e 2019. O texto é composto de três partes. $\mathrm{Na}$ primeira apresentamos a comunidade Caveira, seu processo de reconhecimento como remanescente de quilombo e os sentidos associados pelas lideranças locais à construção e ao funcionamento da escola. Na segunda, descrevemos como foi sendo construído o cotidiano escolar em suas múltiplas dimensões, isto é, o currículo escolar em ações práticas nos anos de funcionamento da escola que pudemos observar durante a gestão da diretora 1, de 2017-2019. Na terceira parte, com base nas trocas de gestão na Secretaria Municipal de Educação e na escola, com a diretora 2, iniciou-se um processo de debate que tinha por intenção a construção de um currículo que representasse, assim como determina a legislação, a especificidade étnico-cultural do grupo, ou, mais prosaicamente, a "singularidade" do quilombo Caveira. Na última seção apresentamos as considerações finais que, de certa forma, trazem apontamentos importantes para o campo de pesquisas da educação quilombola.

\section{O QUILOMBO CAVEIRA-BOTAFOGO E OS SENTIDOS CONFERIDOS À ESCOLA}

A comunidade Caveira está localizada na área rural do município de São Pedro da Aldeia, no estado do Rio de Janeiro. Atualmente, vivem no seu território de 220 hectares cerca de 220 famílias, ou aproximadamente 1.200 pessoas (Costa, 2016). Segundo a Coleção Terras de Quilombo (Costa, 2016), os quilombolas dessa comunidade são, em sua maioria, descendentes de indivíduos negros escravizados que já ocupavam essa área mesmo antes da abolição da escravatura, trabalhando na lavoura e na criação de pequenos animais. Com o passar do tempo, em razão de algumas vendas de terrenos e casamentos exógenos, a comunidade passou a receber algumas pessoas de fora, o que não chegou a impactar os laços de parentesco entre os moradores, nem as práticas de cultivo e criação das famílias de seu tronco original ${ }^{3}$. Tais aspectos teriam sido fundamentais para a resistência da comunidade na luta contra as sucessivas tentativas de expulsão por parte de supostos donos das terras que chegaram à região em diferentes momentos. Entre as décadas de 1950 e 1970, os conflitos fundiários atingiram seu ponto crítico, tendo havido um movimento de resistência aos invasores pela estreita vinculação da comunidade ao sindicalismo rural (Arruti e Figueiredo, 2005).

2 Nos documentos apresentados pelas lideranças, o nome da comunidade aparece como Caveira-Botafogo. No texto assumimos Caveira, tal como aparece na Coleção Terras de Quilombo (Costa, 2016) e no processo de certificação da Fundação Cultural Palmares.

3 O laudo antropológico do quilombolo Caveira (Carvalho e O'Dwye, 1998) indica quatro troncos familiares originais: os Silveira, os Santos, os Marcianos e os Ivo. Já os dados coletados em campo apontam para as seguintes famílias: Silveira, Santos e Souza. 
De acordo com Arruti e Figueiredo (2005), a comunidade quilombola Caveira foi formada por um processo de desagregação da Fazenda Campos Novos, composta de negros escravizados que permaneceram nas terras abandonadas por seu antigo dono. Segundo relatos colhidos na comunidade, o processo de reconhecimento iniciou-se nos idos dos anos 1990 e teve forte participação do governo estadual da época, representado pela Governadora Benedita da Silva, que teria sido informada das lutas localizadas das famílias de Caveira em relação à posse das terras. Esse processo chegaria em 2002 à Fundação Cultural Palmares, que, então, iniciou o processo de certificação da comunidade como remanescente de quilombo, finalizando-o no ano de 2004. Esse processo foi efeito de difusão e surgimento de novas comunidades quilombolas na região, em função do reconhecimento da presença de condições semelhantes e, portanto, de direitos aos respectivos territórios ocupados:

Comunidades quilombolas vizinhas ao Quilombo de Caveira - entre elas Rasa, Botafogo e Preto Forro - compartilham uma história semelhante e também participam da reivindicação da titulação de suas terras. A comunidade Preto Forro, situada no bairro rural do Angelim, em Cabo Frio, já obteve a titulação de suas terras como quilombola. (Costa, 2016, p. 3)

Arruti e Figueiredo (2005) apontam para o fato de que o reconhecimento de Caveira como remanescente de quilombo não teve relação com uma reivindicação da comunidade ${ }^{4}$, mas com sua caracterização histórica e sociológica pautada nos seguintes itens:

- predominância de população negra e descendente de escravos;

- memória social da escravidão ligada a um determinado território geográfico e social;

- permanência daquela população em um mesmo território por gerações, com tendência a recuar até o período da abolição ou mesmo antes deste;

- predominância dos laços de parentesco como vínculo integrador da população em apreço.

Por outro lado, a forte participação de uma das lideranças políticas da comunidade na luta pelo reconhecimento quilombola local teria alavancado sua candidatura a vereador da cidade, conferindo-lhe acesso às redes do campo político e da gestão pública municipal, potencializando, assim, a visibilidade da causa. Roberto Santos, mais conhecido como Robertão e atual presidente da Associação dos Remanescentes do Quilombo Botafogo-Caveira (ARQBC), com o capital político de vereador de São Pedro da Aldeia, foi a Brasília a fim de buscar o reconhecimento e a certificação. Ele comenta que: "Com essa publicação, aí sim, nós tínhamos uma coisa oficial, naquele momento sabíamos que poderíamos então trabalhar, porque antes ninguém se mexia" (ago. 2019). Todavia, desde a certificação pela Fundação

4 A autoatribuição feita pela própria comunidade no processo de reivindicação de reconhecimento como comunidade quilombola, conforme o decreto 4.887, de 20 de novembro de 2003, não foi determinante no processo de certificação de Caveira. 
Cultural Palmares em 2004 até os dias de hoje, os quilombolas de Caveira ainda não obtiveram a titulação definitiva das terras pelo Instituto Nacional de Colonização e Reforma Agrária (INCRA), fato comum entre a quantidade de comunidades certificadas e ainda com terras não tituladas no país (Jorge, 2016). Isso os coloca, assim, a meio caminho entre o processo de certificação e o de titulação das terras, tornando sua luta inconclusa, viva, não apenas quanto ao objetivo derradeiro de titulação das terras, mas para a própria construção de um quilombo reconhecido e pulsante ${ }^{5}$.

Nesse sentido, é interessante destacarmos como se constroem e circulam as noções e saberes do que é "ser quilombola" entre comunidades remanescentes de quilombo do estado do Rio de Janeiro, tornando algumas delas modelos de autogestão para outras que ainda estão em processo de reafirmação identitária, como parece ser o caso em Caveira. Nesta, lideranças citaram alguns quilombos reconhecidos que obtinham retornos em termos de desenvolvimento local com o turismo de base comunitária, o artesanato próprio, a culinária, a venda de produtos típicos, práticas culturais específicas etc. O quilombo de Campinho da Independência, no município de Paraty, é uma referência muito presente nas falas dos membros dessas comunidades $^{6}$. Orientado por esses modelos, Caveira vem produzindo atividades nessa direção, a saber: o Samba do Quilombo, que ocorria no primeiro domingo do mês; passeios e trilhas na região; corridas e visitas às casas daqueles que mantinham pequenos cultivos de raízes, hortaliças, frutas e pequenos animais para consumo próprio e para venda em reduzida escala.

Apesar de conquistarem da Fundação Cultural Palmares o reconhecimento e a certificação como remanescentes ${ }^{7}$, a comunidade ainda não obteve retornos simbólicos e materiais diretos, bem como permanece carente de infraestrutura pública, como saneamento básico. As lideranças indicam que até 2009, o fornecimento de iluminação era ainda precário. O Sr. João Carlos, filho de Dona Almerinda, lembra que a energia elétrica foi instalada nas residências em 1981 ou 1982: "Eu fui ter televisão em casa eu já era adulto, ela era à bateria". "Fazia tudo com vela, com lamparina, com lampião". Diz que sua mãe o lembra de que até a chegada do fornecimento da energia elétrica, as noites de lua cheia eram aproveitadas para passear e visitar os parentes (Costa, 2016, p. 11).

A partir da Constituição de 1988, que identificou este novo sujeito de direitos - os remanescentes de quilombo -, foi progressivo o surgimento de comunidades quilombolas em todo o país, o que tornou possível uma luta que reivindica distribuição, reconhecimento e serviços do estado (Arruti, 2006; Fraser, 2007). O

5 O ressurgimento conservador no plano sociopolítico brasileiro torna-se uma dificuldade para a luta e a conservação de direitos das comunidades quilombolas e povos indígenas no contexto atual (Jorge, 2016; Brandão e Jorge, 2018).

6 Experiências em outros quilombos difundem-se e tornam-se referências de autogestão e educação.

7 A categorização como quilombola traz consigo algumas diferenciações de tratamento pelo poder público - Programa Brasil Quilombola (PBQ-2004) — e a Agenda Social Quilombola - decreto n. 6.261/2007. 
processo de luta capitaneado pelas lideranças da comunidade em busca do acesso às políticas públicas diferenciadas vem sendo associado não somente ao objetivo central de titulação das terras ocupadas, nem somente ao reconhecimento étnico-cultural de sua identidade e seus saberes tradicionais, mas a todos os processos associados ao que podemos chamar de anseios de desenvolvimento local, dos quais aquela zona rural fora sempre alijada.

A busca pelo reconhecimento e por direitos das comunidades quilombolas produziu uma nova gramática social legítima. Gramática esta que permitiu um novo tipo de organização "de semelhantes", de uma comunidade, numa sociedade de indivíduos que lutam perante o Estado para reivindicar proteção e direitos sociais (Castel, 2005). Talvez estejamos diante de um mecanismo similar ao que Leite Lopes (2004) denominou, no contexto das lutas ambientalistas, de "ambientalização" dos conflitos sociais, isto é: antigas demandas por direitos de cidadania (como acesso a bens básicos, saneamento, renda mínima, educação etc.) que se ressemantizavam em razão do surgimento dos novos direitos ambientais, de novos conceitos associados a eles e da produção de novas identidades em espaço público. Parafraseando Leite Lopes, poder-se-ia afirmar a existência de um processo de "quilombização" de velhas demandas sociais locais e de proteção social para esses atores com poucos recursos materiais, simbólicos e organizacionais. Tal movimento, que chamamos aqui de "quilombização", ou a emergência dos "remanescentes"(Arruti, 2006), guardadas as devidas diferenças, assemelha-se à noção de "índios misturados" do Nordeste desenvolvida por Oliveira (1998), estando ambos os autores ancorados no conceito de etnicidade (Barth, 2000).

A demanda pela escola local em Caveira foi um dos elementos incorporados à luta por direitos básicos, potencializados a partir da certificação quilombola. Segundo relatos de alguns moradores, a escola era uma antiga demanda da comunidade, já que a mais próxima distava $14 \mathrm{~km}$ de Caveira. O velho pleito somente ganhou força após o processo de certificação da comunidade em 2004. Então, em um terreno doado por uma das remanescentes, Dona Rosa Geralda da Silveira, a prefeitura construiu em 2013 a escola que atende atualmente à Educação Infantil e aos primeiros anos do Ensino Fundamental. A busca e a conquista da escola desejada há gerações potencializou-se exatamente por ter sido uma luta "quilombizada", de uma comunidade reconhecida, que obteve no interior dessa nova gramática os capitais simbólico e social necessários para a conquista de antigas demandas locais.

O nome da escola da comunidade homenageou Dona Rosa Geralda da Silveira, produtora de farinha local e uma das protagonistas das lutas da comunidade Caveira, anteriormente à proteção fundiária oriunda da ressemantização da categoria quilombo. A escola foi inaugurada em 28 de maio de 2013 e vem, desde então, atendendo crianças quilombolas e não quilombolas que residem no território, nas redondezas e nos outros quilombos próximos.

As diretrizes da EEQ pensam a escola como um espaço de mediação e de reconstrução das identidades étnicas por meio da incorporação e da ressignificação de práticas e saberes que dialoguem com a realidade local, indo além da prescrição do currículo básico para formar as novas gerações das famílias quilombolas e não quilombolas. Elementos agenciadores das identidades quilombolas compõem 
o campo do reconhecimento de tais grupos no Brasil (Jorge, 2016). Parte da literatura tem demonstrado como danças e festas, por exemplo, têm servido não propriamente para "resgatar" o passado, mas para recriar novas práticas culturais e tradições que legitimam a condição de quilombolas e produzem maior coesão interna em razão de identidade social compartilhada. Lara et al. (2009) descrevem na comunidade quilombola Paiol de Telha (reconhecida como quilombola desde 1988) a criação de uma companhia de música e dança chamada "Kundun Balê", explicando que sua criação veio justamente para preencher uma lacuna na questão da suposta "ausência da cultura negra" na comunidade. Na mesma direção, Maroun (2014) demonstrou o papel do jongo como elemento de reestruturação da memória coletiva e da identidade quilombola em Bracuí. O jongo praticado hoje é um processo de ressignificação, já que no passado ele tinha forte apelo mágico-religioso ligado às religiões de matriz africana. Essa prática tornou-se elemento central na formação identitária de crianças e jovens quilombolas de Bracuí, contribuindo para a permanência da comunidade na luta pelo território e para a visibilidade pública de suas demandas. Em certo sentido, a escola de Caveira, como uma das mediadoras da produção da identidade quilombola, pode ser lida como uma representação em microescala dos processos de reconstrução de identidades quilombolas nesses territórios ${ }^{8}$.

Embora a comunidade Caveira tenha tido seu reconhecimento formal como quilombola anteriormente à construção da escola, esta passa a ocupar um lugar central (não o único, mas talvez o principal) na construção simbólica da identidade quilombola da comunidade. Se colocarmos em diálogo tal argumento com a concepção da teoria durkheimiana clássica sobre o conceito de educação (Durkheim, 2013), encontramo-nos diante de uma inovação, pois, nessa teoria, o papel da educação seria de conservação de valores e disposições caros à sociedade política. $\mathrm{E}$, para a escola quilombola, sua função social estende-se para além da reprodução, produzindo, nesse contexto de análise, uma novidade: a tentativa de construção de uma cultura local quilombola pautada pela estrutura dos troncos familiares, pelo diálogo com os mediadores comunitários, pela inventariação e pela ressignificação de práticas e de elementos associados às culturas locais e/ou à memória da escravidão e da luta pelo território.

Com esse apelo de construção da identidade quilombola da comunidade, suas lideranças passam a construir imagens sobre um desejável funcionamento da escola e sobre sua participação em um possível currículo escolar. Não bastaria criar uma escola e nomeá-la como quilombola; ela apresenta-se com um sentido mais ativo para as lideranças, isto é, deveria ser um ponto de construção e consolidação da própria identidade quilombola de Caveira na produção tanto de reconhecimento interno, entre os moradores do próprio grupo, quanto de reconhecimento externo, ao considerar o poder público e a sociedade em geral.

8 O artigo 68 do Ato das Disposições Constitucionais Transitórias (ADCT) foi o responsável por marcar o início da abertura pública de um leque de discussões que se multiplicam até os dias atuais (Jorge e Brandão, 2016). 


\section{IDENTIDADE QUILOMBOLA NAS PRÁTICAS ESCOLARES (2017-2018)}

Desde a nossa entrada em campo em 2017, chamou-nos atenção o fato de os sentidos atribuídos à EEQ apresentados pela escola estarem associados a elementos não propriamente locais ou comunitários, como o cotidiano da comunidade ou o histórico das lutas de Caveira. Os sentidos evocados por seus símbolos, imagens expostas nas paredes da escola, festividades, literatura e material didático referiam-se a elementos gerais associados ao quadro interpretativo dos movimentos negros ou das buscas da ancestralidade africana. Especialmente, duas matrizes de significado correntes na construção de seu currículo em ação foram, por nós, distinguidas no acompanhamento etnográfico que fizemos entre os anos de 2017 e 2018, quando estivemos dentro da escola durante a gestão da diretora 1. Uma primeira era baseada na construção da narrativa de reconhecimento e presentificação da ascendência africana e toda a sorte de símbolos que poderíamos, na falta de melhor noção, chamar de "africanidades", disponíveis no acervo e nos movimentos culturais de nosso país. E a segunda baseava-se numa agenda de reconhecimento, respeito à diversidade e empoderamento da identidade negra, o que poderíamos denominar de disseminação de valores antirracistas.

Apesar do esforço da gestão da escola e dos docentes, era notável o fraco movimento de "quilombização" das práticas pedagógicas, demanda que existia, entre outros, na gestão municipal, no movimento negro do município, nas lideranças da comunidade, nas incursões da mídia ${ }^{9}$ e em pesquisadores, como nós, que procuravam a escola exatamente para conhecer um caso de educação diferenciada. Por outro lado, os profissionais escolares davam respostas possíveis em seu cotidiano com as ferramentas pedagógicas que portavam, com um senso prático do magistério, e com base em algumas reificações associadas ao senso comum sobre o que seria a EEQ. Coerente com sua formação e em dúvida sobre qual seria o desenho prático de uma "pedagogia quilombola", uma das professoras da Educação Infantil, em uma entrevista, disse: "Antes de serem quilombolas, eles são crianças, e eu educo crianças” (ago. 2019). Tal declaração remete justamente ao desafio de conciliação entre o universal (currículo básico) e o particular (saberes locais) quando tomamos a EEQ como campo analítico, isto é, o desenho de uma educação diferenciada.

A imagem da África era frequentemente evocada no cotidiano da escola, em suas festividades, na decoração e imagética, nos materiais didáticos e paradidáticos, aludindo a uma ancestralidade comum das crianças negras e quilombolas da comunidade. A imagem existente na entrada da porta principal da escola é uma pintura cujos dizeres são "Bráfrica, a maior distância é o preconceito", com a imagem dos mapas do Brasil e do continente africano sobrepostos. Nas paredes dispostas ao longo do corredor que leva às salas de aula, ao refeitório, à biblioteca e aos banheiros, há imagens decoradas que fazem alusão ao que poderíamos chamar de imagens fe-

9 Essa informação foi-nos relatada no campo de que era comum aparecerem jornalistas solicitando conhecer a escola quilombola da região. 
mininas também associadas às "africanidades". Ainda no corredor, foram observados murais com os resultados dos trabalhos desenvolvidos ao longo dos trimestres. No ano de 2017, quando de nossa entrada em campo, os temas trimestrais do projeto pedagógico eram: "Mãe Negra sim"; "Lendas"; e "Consciência Negra”. Na festa da consciência negra de 2017, todas as turmas da escola realizaram uma apresentação ao público no formato de desfile. Este foi iniciado com uma aluna portando a bandeira do Brasil, e depois cada uma das turmas desfilou com a bandeira de um país africano e com roupas que dariam sentido genérico a uma ideia de África. Além de estarem enrolados com as bandeiras, os alunos traziam plaquinhas penduradas ao pescoço com o nome dos países das respectivas bandeiras que carregavam. As festas, em geral, são momentos potentes de apresentação desses signos e imagéticas sobre o que é interpretado como educação quilombola na escola.

Se o tema África era presente, outro tema correlato era o das práticas curriculares de valorização da negritude, mas, sobretudo, destacavam-se aqueles associados a uma pedagogia de cunho antirracista, a um tipo de formação das sensibilidades de respeito à diversidade étnico-racial. A associação direta entre o conceito de quilombo e as bandeiras dos movimentos negros fez com que o tema da diversidade étnico-racial alcançasse um status de primeiro grau nas formas de apreensão desse debate nas práticas curriculares vivenciadas, principalmente nos momentos de festividade da escola. Conforme nos lembra Lívio Sansone (2003), nos últimos anos têm sido divulgados novos trabalhos sobre as identidades e a cultura "dita" negra no Brasil, cujos símbolos e artefatos associados a uma "negritude" se têm tornado mais visíveis do que nunca: as cores do axé, o cabelo rastafári, a roupa de estilo inspirado numa África homogênea e a roda de capoeira. Estes são exemplos mais salientes, além de testemunharem um crescimento de interesse pela "África", pelo "Atlântico Negro" e pela história africana.

O texto curricular, entendido como espaço contestado e como a totalidade das experiências ${ }^{10}$ e práticas escolares (Silva, 2003), era atravessado pelo tema das "africanidades", com o referente de origem racial e cultural. Entendendo os limites entre os ideais normativos da EEQ e a prática escolar dos docentes, podemos dizer que esse tratamento, em alguns momentos, acabava por reproduzir essencialismo e exotismo das imagens e textos das culturas afro-brasileiras. Poder-se-ia nomear o currículo, para usar a expressão de outra pesquisadora que também estudava a escola na mesma época, de "um currículo quilombola exótico". Todavia, devemos entender que, naquele momento, era a forma de apreensão e agenciamento da EEQ possível para o corpo docente da escola e, como sabemos, a entrega de qualquer política depende da mediação e da apreensão dos agentes na ponta do processo, que agem com relativa autonomia e discricionariedade (Lipsky, 1980).

A análise aqui não pretende utilizar estratégias de desconstrução de narrativas, de identidades nacionais, étnicas e/ou raciais como as que têm sido desenvolvidas nos campos teóricos do pós-estruturalismo, dos estudos culturais e dos estudos

10 Totalidade que passa pela arquitetura, livro didático e paradidático, lições orais, orientações curriculares oficiais, rituais escolares, recreios, datas festivas e comemorativas etc. 
pós-coloniais. A intenção aqui é demarcar que esse processo de experiência e construção curricular na escola enfrenta toda a sorte de influências e formas possíveis de apreensão das gramáticas culturais, que circulam e estão disponíveis à apreensão e à apropriação pelos docentes e demais atores escolares. Um efeito positivo desse processo era o de dar visibilidade, reconhecimento e positivação de ser negro ou negra naquela comunidade quilombola e na sociedade.

O trabalho de campo indicou que havia agenciamento tanto para educar sensibilidades antirracistas quanto para socializar valores e leituras mais conciliatórios e mais aproximados da noção de "tolerância", "diversidade" e "assimilação" (Candau, 2011). Os temas da África e do respeito à diversidade étnico-racial serviam à produção de consensos locais, levando-se em conta o perfil das famílias atendidas pela escola (quilombolas e não quilombolas). A diretora 1 revelou-nos que eram delicadas as alusões ao passado africano vinculado a danças que pudessem ser associadas às religiões de matriz afrodescendente, pois naquela escola era alta a presença de famílias evangélicas. É sabido que as religiões evangélicas e neopentecostais têm crescido no Brasil, e no município de São Pedro da Aldeia não é diferente. Segundo relatos de servidores da secretaria de educação, o número de indivíduos de filiação evangélica teria crescido consideravelmente. No último censo do Instituto Brasileiro de Geografia e Estatística, de 2010, esta já era a religião majoritária (42,9\%) na composição por filiação religiosa no município (IBGE, 2012). Esse número global no município talvez se refletisse na composição das famílias da escola. A postura conciliatória da diretora, para além do fato da presença de famílias evangélicas, era produto de suas próprias associações entre "africanidades" e noções estereotipadas sobre a religiosidade de matriz afrodescendente. Isso porque a etnicidade quilombola não está intrinsecamente e nem diretamente associada a nenhuma religião de matriz afrodescendente e muito menos a uma temporalidade da escravidão (Jorge, 2016). Observemos um relato da entrevista com a diretora 1, no qual ela expressa aquilo que nomeou como resistência de parte das famílias evangélicas que frequentam a escola e suas tentativas de mediação:

A gente tem 30\% de remanescente quilombola, o restante não é. E tem um grupo grande de evangélico e eles têm um pensamento distorcido sobre africanidade. Acham, muitos deles, que é macumba, a verdade é essa. Quando a gente faz as nossas festas, a gente vê que poucos pais trazem os filhos, porque acham que não é necessário. As danças nós mandamos para casa pedindo autorização para a criança dançar, muitos não deixam as crianças dançar; às vezes, até vêm participar da festa, mas a criança não pode participar da dança. Então, assim, a gente conseguiu diminuir isso daí. Eu coloco para eles: "Eu também sou cristã, só que é cultura que a gente está passando para criança". Ai passo para eles aquilo que a gente vai colbendo de informação de alguns costumes, falando sobre a questão da comida na encruzilhada. Por qual motivo ocorria isso? As pessoas colocavam ali para que os negros em fuga passassem e se alimentassem, pois numa encruzilhada, onde ele passasse, em qualquer posição que ele passasse, ele ia passar por aquela comida que estava ali. A música é outro exemplo, as muisicas são o quê? São expressões do sofrimento deles, quando o irmão estava 
apanhando, quando o irmão estava lá no tronco, então é uma música de expressão de sofrimento pelo que o outro estava passando. Então a gente está tentando fazer esse trabalho, primeiro para colocar na cabeça dos pais a questão quilombola, do que é e o que não é, para eles conseguirem entender. (nov. 2017)

A gestão da escola nesse período observado não era diretamente ligada às demandas e lutas da comunidade - isso nos foi relatado inúmeras vezes pelas lideranças da comunidade. A diretora 1 , como já dito, assumia uma postura mais conciliadora, o que, de certa forma, contribuía para a consolidação de um currículo antirracista na medida em que seu discurso procurava assimilar as religiões afrodescendentes pelo viés de sua dimensão cultural, socializando saberes vinculados às "africanidades". Isto é, pela alusão a uma categoria explicativa neutra de cultura, ela tentava legitimar a presença de elementos de uma noção de estética africana. Essa "via pela cultura" tem sido a forma de presença dessas religiões no espaço público. É o que ocorre mais claramente na Bahia, onde o candomblé faz parte de uma "baianidade" oficialmente promovida pelo estado, via de presença da religião no espaço público (Giumbelli, 2008). Entretanto, no caso aqui tratado, a diretora 1 mencionou, apesar de sua perspectiva conciliatória, reações preconceituosas de algumas famílias à estética vinculada às religiões afro na escola.

Como todo currículo é espaço contestado e local de disputas entre os diferentes atores sociais e instituições que interagem com a escola, a diretora 1 tentava dialogar com, ou imunizar-se contra, críticas às interpretações contrárias às da comunidade escolar em relação à pauta da educação quilombola empreendida. Tais críticas eram respondidas pelos temas dos projetos educativos trimestrais com clara positivação do que a gestão pensava ser a identidade quilombola da escola. Por exemplo, um dos temas foi: "Quilombolas sim, por que não?”.

Eu estava pesquisando, e a gente ainda pensou em trazer elementos com relação ao tema "Quilombolas sim, por que não?". Porque a gente ainda tem alguns pais que acham que [...]. Eu tenho um pai que tirou o seu filho esse ano da escola. Tirou e perguntou: "Vocês vão trabalhar a questão quilombola com os alunos?" Vamos! Vamos ter que trabalhar, a nossa escola tem um titulo em proposta, se botamos esse titulo, a gente tem que trabalhar, fazer jus, né? Ai, ele não ficou muito à vontade: "Ah, eu gosto muito da escola, mas não podemos; ai eles querem vir, pois os coleguinhas vêm". Ai eu disse: "Fica à vontade, mas, agora, deixar de fazer, deixar de trabalhar o tema quilombola a gente não pode". (Diretora 1, set. 2018)

Nesse período, o currículo escolar foi sendo canalizado para as duas narrativas já descritas: saberes e práticas pedagógicas relacionados à noção de "africanidades" e à valorização da negritude com a perspectiva antirracista. A diretora 1 e o corpo docente, segundo seus relatos, buscavam materiais na internet, em feiras de livros e livrarias para trabalhar a temática afro-brasileira e, em alguma medida, a questão quilombola em sentido mais amplo. Essas experiências e tentativas demonstravam que o trabalho pedagógico era desenvolvido sem ter relação direta com a comunidade de Caveira, e que a própria comunidade não atuava nesse processo de coeducação. 
Sem conhecimentos e sem formação teórica sobre o tratamento da temática quilombola, a direção, com o corpo docente na época, tomava decisões de maneira discricionária e, como vimos, com base em ações conciliadoras e assimilacionistas. Nesse sentido, a comunidade Caveira seria apenas uma referência quilombola no contexto escolar, sem que houvesse qualquer tratamento especial dado ao seu contexto sócio-histórico-cultural específico. Por outro lado, a diretora 1 comentou que a comunidade não ajudava a escola nesse processo de construção de um currículo quilombola. Os caminhos que a direção escolar tomou sugerem, portanto, um afastamento consciente da dimensão da luta quilombola local, mas também reflexos de uma política pública pouco acompanhada, sem suporte ou gerenciamento da Secretaria Municipal de Educação na época dessa gestão.

Eles [Secretaria de Educação] lá não têm muito suporte para dar pra gente. [...] A gente deveria ter uma coordenação de educação quilombola para estar norteando os professores que vêm para trabalhar, a gente e a DIPPPIR ${ }^{11}$, que trabalha com a secretaria de inclusão, mas eles atendem educação do campo e tal. Tinha a Bethe, que fazia um trabalho muito bom, mas saiu. (Diretora 1, set. 2017).

Diante da falta de apoio e de assessoramento da Secretaria de Educação, a solução encontrada pela diretora era trabalhar com enfoque na diversidade étnico-racial, assimilando a esse amplo espectro a identidade quilombola: "você está falando que não toca muito profundamente nas questões quilombolas porque são crianças em idades muito pequenas, mas o currículo oficial tem questões e temas quilombolas?" (Pesquisador, out. 2017).

Tem muitas datas comemorativas, é onde a gente puxa mais e trabalha. Discriminação racial, ai vem 13 de maio, a gente vai buscando esses temas e a gente vai colocando. Porque o que eles mais colocam dentro do currículo é a questão de não deixar a identidade morrer, de estar sempre falando sobre. (Diretora 1, out. 2017)

Essa estratégia da direção gozava de certo prestígio entre as famílias dos/ as alunos/as, quilombolas e não quilombolas. Nas festividades, momentos ricos da etnografia, podíamos encontrar famílias inteiras no espaço da escola. Certa vez, ouvimos a seguinte frase de uma mãe de aluno, identificada como branca e não quilombola: "Não vejo nenhum problema nesta escola, ela só ensina a gente a não ter preconceito" (nov. 2018).

Do ponto de vista das lideranças políticas da comunidade, a idealização da África e a prática de uma pedagogia antirracista presentes no texto curricular da escola, apesar de importantes, enublavam questões propriamente locais ou da luta particular do quilombo Caveira-Botafogo - "quilombola pra inglês ver", disse-nos uma das lideranças ligadas à associação dos moradores (nov. 2018). A identidade quilombola era, portanto, assimilada na escola pelo viés da valorização das "africanidades". Os significados que circulavam na própria comunidade em

11 Diretoria de Políticas Públicas e Promoção de Igualdade Racial. 
relação à escola, assim como os significados dos atores da comunidade escolar em relação aos seus primeiros anos de funcionamento, demonstravam certo incômodo com esse caminho traçado pela direção. Valorizar a negritude e trabalhar com uma pedagogia supostamente antirracista sem considerar a memória e a história da comunidade quilombola Caveira produzia uma espécie de descolamento da escola do território étnico no qual se inseria. Como nos lembra Arruti (2017), a simples classificação ou nomeação diferenciada de uma escola como quilombola não necessariamente a torna diferenciada em seu currículo ou em suas práticas pedagógicas.

\section{EM BUSCA DA EDUCAÇÃO DIFERENCIADA (2019)}

Nesta parte do texto trabalharemos com os movimentos de uma nova gestão na escola e na Secretaria Municipal de Educação, que marcaram o início de uma tentativa de (re)estruturação do currículo da escola quilombola. O novo secretário de educação do município, Alessandro Teixeira Knauft, empossado em setembro de 2018, deparou-se com o problema da saída da diretora 1 em maio de 2019: ela não havia conseguido os votos necessários para o exercício de um novo mandato. Diante desse problema, nomeou, sem eleição, uma nova diretora, que aqui nomeamos de diretora 2. Afirmando ser comprometido com a implementação de uma educação diferenciada na escola quilombola, estruturou uma equipe pedagógica ${ }^{12}$ da Secretaria de Educação, que tinha como missão dar apoio à diretora 2 e aos docentes da escola na (re)estruturação de um currículo afinado com as Diretrizes Curriculares Nacionais para a EEQ e com a comunidade Caveira. A motivação dessa ação política decorria da crítica segundo a qual o trabalho desenvolvido até então pela escola não contemplava uma educação diferenciada para atender às demandas daquela comunidade.

Cabe aqui o relato de algumas nuances relevantes que antecederam esse processo de formação, acumuladas em nossas incursões etnográficas. $\mathrm{O}$ novo secretário de educação, ao tomar como desafio a construção de um currículo quilombola para a escola, aproximou-se da escola e da Diretoria de Políticas Públicas e Promoção de Igualdade Racial (DIPPPIR), localizada na Prefeitura de São Pedro da Aldeia. A DIPPPIR, entre várias ações na prefeitura, também se associa a pautas do movimento negro da cidade e realizou, no fim de julho de 2019, a 5a Edição do Prêmio Dandara Guerreira ${ }^{13}$. A presença do secretário acompanhado da diretora 2 da escola quilombola, bem como o seu discurso, que ressaltou a importância do evento, do movimento negro e da escola quilombola, são indícios de que a educação quilombola entrava na pauta de sua gestão.

12 Formada pelos coordenadores de história, pela coordenadora de Avaliações Internas e Currículo e coordenadoras dos demais setores pedagógicos da Secretaria Municipal de Educação de São Pedro da Aldeia.

13 Informações sobre o evento no link: http://pmspa.rj.gov.br/5a-edicao-do-premio-dandara-guerreira-e-sucesso-em-sao-pedro-da-aldeia. 
Essa aproximação foi também observada por nós em sua presença na Festa da Roça (Festa Junina) da escola quilombola ${ }^{14}$. Nesse evento, o secretário de educação apresentou-nos pessoalmente sua equipe pedagógica e disse que "a escola era quilombola somente no nome, e suas particularidades seriam [até o momento] apresentadas somente pelo doce de leite e pela goiabada" (ago. 2019). Enfatizava, enquanto gestor, que a escola, embora situada em território quilombola e com nome quilombola, não se diferenciava em relação às outras da rede municipal.

O fato de o prédio estar em uma comunidade quilombola não fazia a escola ser quilombola; isso nos incomodava muito. Então, a primeira medida foi trazer essa discussão de maneira um pouco mais profunda. Estamos fazendo uma movimentação para que a identidade quilombola esteja forte, pois a pior coisa que se tem para uma cidade é ter uma história apagada, sem referência. (Ago. 2019)

Destacamos que o adjetivo "quilombola" presente no nome da escola parece produzir efeitos e dilemas, tanto para gestão central quanto para as diretoras que passaram pela referida instituição. Como pudemos observar, o atual secretário enfatiza que a escola não poderia ser quilombola apenas no nome. Mesmo durante a gestão anterior, na qual a diretora 1 se sentia desassistida e sem o devido conhecimento e apoio pedagógico da secretaria de educação, ela tentava, de alguma forma, realizar apropriações no currículo daquilo que entendia como quilombola. Ela também se sentia compelida a trabalhar a temática quilombola, como disse certa vez: "Vamos ter que trabalhar, a nossa escola tem um título em proposta, se botamos esse título, a gente tem que trabalhar" (set. 2017). A diretora 1, quando interrogada sobre como ali chegara para dirigir a escola, relatou-nos que tinha experiência de gestão, era professora concursada do município e acreditava que ser negra tivesse pesado em sua escolha pelo antigo secretário, mesmo que ela não tivesse envolvimento algum com a questão quilombola ou com o movimento negro da região - denotando, entre outros motivos, a associação direta entre ser quilombola e ter a pele negra. Outro exemplo nesse sentido deu-se quando conhecemos a diretora 2, uma mulher que seria heteroidentificada como branca, com os cabelos lisos e tingidos de loiro. Numa conversa informal ela justificou que também tinha negros em sua família sem nada perguntarmos. Interessante marcar que a escola quilombola, a partir do momento que é assim classificada, gera certas obrigações na determinação de seu currículo e alguns entraves ou respostas associados às políticas de representação do movimento negro, como, por exemplo, quem tem legitimidade para dirigir uma escola quilombola.

$\mathrm{Na}$ direção da construção de um currículo diferenciado como uma necessidade imediata de resposta, a secretaria de educação publicou no diário oficial do município, no dia 27 de setembro de 2019, a comissão técnica para colaboração na construção da Proposta Curricular Quilombola Dona Rosa Geralda da Silveira. A comissão, além dos membros da equipe pedagógica da secretaria, da direção da escola e de alguns de seus docentes, contava com a participação de uma represen-

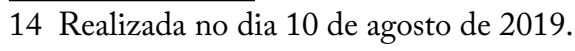


tante da Coordenação Nacional de Articulação das Comunidades Quilombolas (CONAQ), um antropólogo da Universidade Federal Fluminense e uma liderança política da comunidade quilombola, Roberto Santos (Robertão). Estes três últimos, com a equipe pedagógica da secretaria, participaram ativamente de um curso de formação em EEQ voltado apenas para os docentes da escola quilombola. Cada um era responsável por uma dimensão no processo de formação, sob a coordenação e a gestão da equipe pedagógica da Secretaria de Educação. Nossa equipe de pesquisa teve autorização para acompanhar e participar dos trabalhos da comissão, bem como do curso de formação. Assim, tornamo-nos observadores participantes desse rico processo de construção de uma proposta curricular quilombola que contemplasse as especificidades locais. Aqui apresentaremos apenas uma síntese de algumas questões levantadas nesse processo de formação, pois a experiência do curso demandaria descrição e análises mais densas.

O curso tinha como finalidade prática produzir debates e modelos de planejamento sobre a questão quilombola em Caveira com vista à formação de uma proposta curricular diferenciada para a escola. $\mathrm{O}$ processo de formação baseou-se nos seguintes temas geradores: "O que é ser quilombola?"; "A história do movimento quilombola e contexto da comunidade Caveira"; e "Identidade e cultura quilombola: saberes diversos e suas dimensões na prática pedagógica". Os encontros apresentavam o seguinte modelo: na primeira parte, realizava-se uma apresentação em forma de palestra com o antropólogo, a representante da CONAQ e a liderança da comunidade sobre o tema gerador ${ }^{15}$. Depois do intervalo, na segunda parte, todos os participantes dos encontros reuniam-se para pensar ações pedagógicas efetivas a serem realizadas na escola, com base nos conhecimentos apreendidos na primeira parte.

As lições tratadas no curso partiam do pressuposto antropológico de que cada comunidade quilombola tem a sua própria organização social e política, que se modifica com o tempo e não deve ser classificada com base na noção essencialista de "pureza" ou "originalidade" cultural. Sendo assim, o conceito de cultura tratado pelo antropólogo parte de como o grupo se identifica com relação a suas práticas culturais e como externaliza isso, isto é, como estabelece as fronteiras entre si e os outros (Barth, 2000). Trata-se do fenômeno da etnogênese, que pressupõe, por um lado, o reconhecimento na esfera pública e na sociedade civil da imagem do grupo e de seus conflitos locais e, por outro, a sua própria autoatribuição e mobilização política (Arruti, 2006). Essa era a perspectiva que o antropólogo tentou socializar com os docentes da escola quilombola ao longo da formação. Ele incentivava que os docentes tentassem conviver, circular e aprender sobre o quilombo Caveira com a comunidade.

A pauta central dos encontros era, portanto, a de trabalhar os próximos passos para efetivar a construção de um currículo quilombola na e para a Escola Municipal Quilombola Dona Rosa Geralda da Silveira, circulando a todo momento uma noção comum de fazer desta uma "escola, de fato, quilombola". Imagens de que a escola precisava se tornar estruturada ao redor da história e da realidade do quilombo

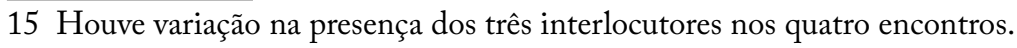


Caveira eram veiculadas, como já dito, repetidamente pela fala do antropólogo e de parte da comissão envolvida no curso. Esse argumento desdobrou-se em todos os encontros e criou dissonâncias entre o corpo docente da escola, na medida em que este estava acostumado a trabalhar a temática quilombola nas festividades (13 de maio; 20 de novembro - Dia da Consciência Negra; festas juninas etc.) e em alguns projetos escolares de valorização e reconhecimento da negritude, textualidades antirracistas e expressões culturais de "africanidades". Por isso, a pergunta inaugural do curso foi provocativa: "O que é ser quilombola?", será que existe uma maneira específica de sê-lo?

De certa forma, o antropólogo incitava os docentes da escola a realizarem levantamentos sobre a memória local e a produzirem narrativas meta-antropológicas para que se tornassem um tipo de matéria-prima a ser articulada com os conhecimentos prescritos pelo currículo básico. Apesar de toda essa experiência de contato com saberes e noções antropológicas socializadas ter sido bem aceita pelos professores, observamos entre eles certo desconforto quanto a como colocar esse novo aprendizado em prática. As tentativas dos docentes da escola na elaboração de planejamentos para "pedagogizar" as temáticas quilombolas nas oficinas do curso geraram um tipo de incômodo tendo em vista que a gramática do antirracismo e das "africanidades" era pregnante e apresentava continuidade com uma dose de essencialismo. Numa dessas reuniões, alguns docentes explicitaram suas dificuldades em dar conta dos conteúdos exigidos pelo currículo básico e as demandas específicas que a escola quilombola exige, o que contribuía para proposições pedagógicas baseadas na perspectiva da diversidade, e não da diferença. Como comenta Candau (2011), o conceito de diversidade evidencia o essencialismo cultural, uma vez que traz implícita a ideia de que a diversidade está dada, que ela preexiste aos processos sociais pelos quais foi criada, de forma que as diferenças sejam assimiladas. Justamente por isso, o antropólogo insistia no argumento de que o eixo de estruturação do debate deveria ser o território quilombola e a memória local sobre a luta de permanência na terra.

Do ponto de vista escolar, para a gestão educacional do município, direção e equipe diretiva, professores e outros profissionais atuantes na escola, a demanda pela construção de um currículo diferenciado com foco na (re)produção do que poderia ser compreendido como "cultura quilombola" de Caveira é transformada num trabalho a mais em seus papéis profissionais. É como se a escola, dotada das funções de educar para a cidadania, para uma vida republicana, para preparar para o mundo do trabalho, também necessitasse agenciar a identidade local e desenvolver um espírito comunitário que ainda, ou mais que nunca, encontra-se frágil localmente, segundo a avaliação das próprias lideranças políticas da comunidade. Nas palavras da Maria, professora quilombola que atua na escola desde 2015: "A gente queria visitar Campinho da Independência para conhecer [...] a gente tem medo de tudo se perder justamente pelo fato de ter muita gente de fora e de não haver algo resgatado aqui” (nov. 2017). Essa fala indica como é latente a sensação de não consolidação de uma identidade positivamente construída, reavivada e ressignificada na comunidade, tanto em relação à história de permanência e luta pelo território quanto na suposta esperança do agenciamento da escola nesse processo de afirmação identitária. 


\section{CONSIDERAÇÕES FINAIS}

Os dilemas, hesitações e tensões que encontramos no caso estudado, ao que tudo indica, não se limitam à experiência escolar que observamos. Vale ressaltar que não há consenso nas pesquisas do campo da educação quilombola sobre o conceito de educação diferenciada para esses grupos. A noção de educação diferenciada pode ser representada por iniciativas isoladas nas quais há relações convergentes entre o projeto político da comunidade e a educação escolar (Oliveira, 2006; Silva, 2012; Maroun, 2016), e, também, existem casos de comunidades em que tais processos inexistem ou estão em construção. Em Caveira, parece que a educação diferenciada que se pretende implementar tem a ver com o próprio processo de construção e reafirmação de uma identidade quilombola que ainda não é um dado consolidado na própria comunidade, estando aberta a todos os possíveis agenciamentos que contribuam para esse curso.

Ao descrevermos e analisarmos o processo de construção social da escola quilombola da comunidade Caveira, ficam questões oriundas especialmente desse campo empírico que podem vir a contribuir para uma agenda de pesquisas sobre EEQ.

A primeira questão que pode ser trazida ao debate é como construir uma educação diferenciada na prática se, de forma geral, as instituições e suas respectivas secretarias de educação não dão atenção diferenciada ao corpo docente e aos gestores dessas escolas, no sentido do que é colocado pelas Diretrizes Curriculares Nacionais para a Educação Escolar Quilombola (Brasil, 2012): docentes e gestores devem ser preferencialmente oriundos das comunidades atendidas pelas instituições. Poder-se-ia dizer que tais profissionais, no caso da EEQ, teriam uma função que iria além de tratar o currículo universal. Com base nesse ideal normativo, eles deveriam ser mediadores/articuladores político-pedagógicos e atuar como tradutores da "gramática quilombola" no currículo escolar. No caso aqui estudado, apesar da iniciativa de formação sobre EEQ em 2019, a implementação de uma educação diferenciada na prática ainda depende de ações individuais de boa vontade e da sensibilização do corpo docente. É fundamental que o corpo docente construa sua identidade em articulação com a comunidade na qual a escola está inserida. Todavia, ainda não temos políticas públicas que forneçam as devidas condições salariais, formativas e materiais para que professores de escolas quilombolas tenham dedicação especial à construção social dessas escolas.

A segunda questão que merece destaque é o fato de escolas quilombolas não atenderem apenas alunos quilombolas. As posturas conciliatórias de gestores e professores que surgem desse suposto embate quilombola e não quilombola acabam por contribuir para o silenciamento das "diferenças", levando as práticas e os saberes escolares para o campo da diversidade étnico-racial. Entretanto, em Caveira, nossa experiência de campo mostra que tanto os temas voltados para a identidade local quanto aqueles que denunciam o racismo estrutural são fundamentais para formar e educar as novas gerações de crianças quilombolas e não quilombolas. Se a escola não pode sozinha superar o racismo, as diversas formas de segregação racial, territorial e de classe, ela pode, ao menos, ser um espaço de formação de novas sensibilidades que visem à construção de subjetividades para se pensar um mundo menos injusto e desigual. 
Deve-se reconhecer a importância das experiências de construção da identidade quilombola inseridas no universo de políticas de reconhecimento social. O tema das "políticas de reconhecimento" é vasto e transcende as experiências nacionais (Honneth, 2009). Resumidamente, reivindicações de reconhecimento identitário não excluem absolutamente as exigências de igualdade socioeconômica, mas articulam-se com elas de maneira complexa (Fraser, 2007). Sendo assim, não é o objetivo deste trabalho questionar a legitimidade das lutas por reconhecimento identitário dos grupos sociais na contemporaneidade, mas tão somente apresentar alguns dilemas que o campo educacional é instado a resolver nas propostas educativas ancoradas nas políticas de reconhecimento.

A terceira questão diz respeito ao que seria uma $\mathrm{EEQ}$, isto é, uma educação diferenciada para cada comunidade quilombola no universo brasileiro. Tendo em vista que as comunidades quilombolas compõem uma diversidade de grupos e que cada uma delas tem um processo próprio de construção e reafirmação identitária, o que é interessante e desejável para uma não necessariamente pode ser estendido a outra. Todavia, algumas aporias estão presentes na emergência da questão quilombola e dos debates sobre a educação quilombola e seus limites. É importante lembrar que parte das dificuldades associa-se ao fato de que os conceitos com que operamos nestes estudos - comunidades quilombolas e educação escolar quilombola, para citar alguns - carregam referências tanto empíricas quanto normativas. A referência empírica compreende a educação quilombola tal como ela se concretiza em cada contexto social - o que tentamos produzir neste texto. Já a normativa é a educação quilombola que normas e leis explicitam como resultado de sentimentos, expectativas e valores coletivos. Frequentemente, essas dimensões, bem como as disputas no campo, encontram-se entrelaçadas na literatura que trata dessa temática (Miranda, 2018).

Em quarto lugar, como advertem Brandão e Jorge (2018), o Brasil vive desde 2016 sob o impacto de forte retomada conservadora, que luta para deslegitimar os avanços legais obtidos em forma de direitos, a partir da constituição de 1988, no campo das relações políticas em geral e das práticas estatais em particular. Esse quadro tem gerado consequências para as comunidades negras que se organizam politicamente em torno de uma identidade quilombola, fundamentalmente pela questão fundiária que envolve esse tipo de luta, assim como para as comunidades indígenas, que também por outros mecanismos e formas legais de uso da terra se tornam empecilhos à grilagem, ao garimpo e ao agronegócio. A análise desse movimento contrário aos direitos étnicos, bem como das resistências dos atores sociais envolvidos com a defesa das políticas públicas de reconhecimento, deve estar presente nas investigações sobre educação diferenciada na atualidade.

Em quinto lugar, deve-se fazer uma advertência quanto aos limites analíticos de um estudo de caso. As experiências da construção da educação escolar quilombola, no quilombo Caveira em São Pedro da Aldeia, apresentam-nos elementos idiossincráticos, portanto não generalizáveis para o conjunto de experiências de educação escolar quilombola do resto do país. Há nessa experiência escolar características observáveis que a diferenciam - mas também a fazem assemelhar-se - a outras inúmeras experiências de educação escolar quilombola, entre as quais: o fato de ser 
uma comunidade quilombola ainda não titulada; o grau de desenvolvimento local de participação dos movimentos sociais; a orientação política do governo municipal. Realizada essa ressalva, cremos, entretanto, como afirma Bourdieu (2004), que seja profícuo interrogar sistematicamente o caso particular, constituído em "caso particular do possível", para retirar dele as propriedades gerais ou invariantes. Nesse sentido, o movimento da comunidade Caveira e sua escola quilombola pode ser lido como um aprendizado de educação diferenciada em processo inacabado, envolto em avanços e retrocessos que compõem os desafios presentes na implementação da EQQ no país.

\section{REFERÊNCIAS}

ARRUTI,J.M. Mocambo: antropologia e história do processo de formação quilombola. Bauru: EDUSC, 2006.

ARRUTI, J. M. Conceitos, normas e números: uma introdução à Educação Escolar Quilombola. Revista Contemporânea de Educação, v. 12, n. 23, p. 107-142, jan./abr. 2017. https://doi.org/10.20500/rce.v12i23.3454

ARRUTI, J. M. P. A; FIGUEIREDO, A. V. Processos cruzados: configurações da questão quilombola e o campo jurídico no Rio de Janeiro. Boletim Informativo NUER, Florianópolis, v. 2, n. 2, p. 77-94, 2005. Disponível em: https://repositorio. ufsc.br/bitstream/handle/123456789/126162/Territ\%C3\%B3rios\%20Quilombolas. pdf?sequence=18isAllowed=y. Acesso em: 30 nov. 2021.

BARTH, F. Os grupos étnicos e suas fronteiras. In: LASK, T. (org.). O guru, o iniciador e outras variações antropológicas. Rio de Janeiro: Contra-Capa, 2000.

BOURDIEU, P. O poder simbólico. Rio de Janeiro: Bertrand Brasil, 2004.

BRANDÃO, A. A.; JORGE, A. L. Congresso conservador e ameaças aos direitos dos quilombolas. Revista de Políticas Públicas, Maranhão, v. 22, n. 2, p.711-731, out. 2018. http://doi.org/10.18764/2178-2865.v22n2p711-731

BRASIL. Ministério da Educação. Diretrizes Curriculares Nacionais para a Educação Escolar Quilombola. Brasília, DF: MEC, 2012.

CANDAU, V. M. Diferenças culturais, cotidiano escolar e práticas pedagógicas. Currículo sem Fronteiras, [S.l.], v. 11, n. 2, p. 240-255, 2011. Disponível em: https:// www.curriculosemfronteiras.org/vol11iss2articles/candau.pdf. Acesso em: 30 nov. 2021. CARVALHO,J.P.F.; D'WYE, C. Os filhos da terra: laudo antropológico de identificação da comunidade remanescente de Quilombo Caveira. Fundação Cultural Palmares, Minc/ Instituto de Terras e Cartografia do Estado do Rio de Janeiro, Rio de Janeiro, 1998.

CASTEL, R. A insegurança social: o que é ser protegido? Petrópolis: Vozes, 2005.

COSTA, L. C. Quilombo da Caveira. Belo Horizonte: NUQ; FAFICH; OJB; FAFICH, 2016. Disponível em: https://www.gov.br/incra/pt-br/assuntos/governancafundiaria/memoria-quilombola. Acesso em: 7 dez. 2021.

DUBET, F. Mutações cruzadas: a cidadania e a escola. Revista Brasileira de Educação, Rio de Janeiro, v. 16, n. 47, p. 289-305, 2011. https://doi.org/10.1590/S141324782011000200002 
DURKHEIM, É. Educação e sociologia. Rio de Janeiro: Vozes, 2013.

FRASER, N. Reconhecimento sem ética? Lua Nova, São Paulo, n. 70, p. 101-138, 2007. https://doi.org/10.1590/S0102-64452007000100006

GIUMBELLI, E. A presença do religioso no espaço público: modalidades no Brasil. Religião e Sociedade, Rio de Janeiro, v. 28 n. 2, p. 80-101, 2008. https://doi. org/10.1590/S0100-85872008000200005

HONNETH, A. Luta pelo reconhecimento: para uma gramática moral dos conflitos sociais. São Paulo: Editora 34, 2009.

IBGE - Instituto Brasileiro de Geografia e Estatística. Censo demográfico 2010. Resultados gerais da amostra. Rio de Janeiro: IBGE, 2012.

JORGE, A. L. O processo de construção da questão quilombola: discursos em disputa. Rio de Janeiro: Gramma, 2016.

JORGE, A. L.; BRANDÃO, A. L. A produção social da "questão quilombola" no Brasil. O Social em Questão, Rio de Janeiro, ano XIX, n. 35, p. 349-374, 2016. Disponível em: http://osocialemquestao.ser.puc-rio.br/media/OSQ 35_2_SL_Jorge_Brand\%C3\%A3o. pdf. Acesso em: 30 nov. 2021.

LARA, L. M. et al. Esporte e lazer na comunidade quilombola Invernada Paiol da Telha: realidade, perspectivas e desafios. In: CONGRESSO BRASILEIRO DE CIÊNCIAS DO ESPORTE, 16., 2009; CONGRESSO INTERNACIONAL DE CIÊNCIAS DO ESPORTE, 3., 2009, Salvador. Anais [...]. Salvador: CONBRACE; CONICE, 2009.

MIRANDA, S. A. Quilombos e Educação: identidades em disputa. Educar em Revista, Curitiba, v. 34, n. 69, p. 193-207, jun. 2018. https://doi.org/10.1590/0104-4060.57234 LEITE LOPES, J. S. (coord.). A ambientalização dos conflitos sociais: participação e controle público da poluição industrial. Rio de Janeiro: Relume-Dumará; Núcleo de Antropologia Política; UFRJ, 2004.

LIPSKY, M. Street-level bureaucracy: dilemmas of the individual in public services. Nova York: Russell Sage Foundation, 1980.

MAROUN, K. A construção de uma identidade quilombola a partir da prática corporal/ cultural do jongo. Movimento, Porto Alegre, v. 20, n. 1, p.13-31,jan./mar. 2014. https:// doi.org/10.22456/1982-8918.39882

MAROUN,K. Jongo e educação escolar quilombola: diálogos no campo do currículo. Cadernos de Pesquisa, São Paulo, v. 46, n.160,p.484-502,2016. http://doi.org/10.1590/198053143357 MAROUN, K.; CARVALHO, E. Experiências de educação quilombola: as relações entre escola e comunidade. Revista da FAEEBA - Educação e Contemporaneidade, Salvador, v. 26, n. 49, p. 87-102, maio/ago. 2017. http://doi.org/10.21879/ faeeba2358-0194.2017.v26.n49.p87-102

OLIVEIRA,J.P.Uma etnologia dos “índios misturados"? Situação colonial, territorialização efluxos culturais.Mana, v, 4, n. 1,p. 47-77, 1998. http://doi.org/10.1590/S0104-93131998000100003

OLIVEIRA, S. N. S. De mangazeiros a quilombolas: terra, educação e identidade em Mangal e Barro Vermelho. 2006. Dissertação (Mestrado em Educação) - Universidade de Brasília, Brasília, 2006. 
SANSONE, L. Negritude sem etnicidade: o local e o global nas relações raciais e na produção cultural negra do Brasil. Salvador: EDUFBA, 2003.

SILVA, G. M. Educação como processo de luta política: a experiência de "educação diferenciada" do território quilombola de Conceição das Crioulas. 2012. Dissertação (Mestrado em Educação) - Universidade de Brasília, Brasília, DF, 2012.

SILVA, T. T. Documentos de identidade: uma introdução às teorias do currículo. Belo Horizonte: Autêntica, 2003.

\section{SOBRE OS AUTORES}

David Gonçalves Soares é doutor em Sociologia pela Universidade Federal do Rio de Janeiro (UFRJ). Professor da Universidade Federal Fluminense (UFF). E-mail: davidsoares1234@gmail.com

Kalyla Maroun é doutora em Educação pela Pontifícia Universidade Católica (PUC-Rio). Professora da Universidade Federal do Rio de Janeiro (UFRJ). E-mail:kalylamaroun@gmail.com

Antonio Jorge Gonçalves Soares é doutor em Educação Física pela Universidade Gama Filho (UGF). Professor da Universidade Federal do Rio de Janeiro (UFRJ).

E-mail: ajgsoares@gmail.com

Conflitos de interesse: Os autores declaram que não possuem nenhum interesse comercial ou associativo que represente conflito de interesses em relação ao manuscrito.

Financiamento: Conselho Nacional de Desenvolvimento Científico e Tecnológico (CNPq) - processo Edital Universal 421065/2016-8 - e Fundação de Amparo à Pesquisa do Estado do Rio de Janeiro (FAPERJ) — processo CNE 202.859/2018.

Contribuições dos autores: Escrita - Primeira Redação e Revisão, Conceituação, Investigação, Metodologia, Validação: Soares, D. G. Escrita - Revisão e Edição, Conceituação, Investigação, Metodologia, Validação: Maroun, K. Administração do Projeto, Escrita - Revisão e Edição, Conceituação, Investigação, Metodologia, Obtenção de Financiamento, Supervisão e Validação, Curadoria dos Dados: Soares, A. J. G. 